\title{
HIGH DEDUCTIBLES INSTEAD OF BONUS-MALUS : CAN IT WORK?
}

\author{
By JEAN Lemaire AND Hongmin ZI \\ Wharton School \\ University of Pennsylvania
}

\begin{abstract}
Holtan (1994) suggests to replace traditional bonus-malus systems by a high deductible financed by a short-term loan. Practical consequences of this proposal are investigated here. Simulation is used to evaluate the efficiency of the Taiwanese Bonus-malus system and the variability of premiums of an average policyholder. Holtan's high deductible system is analysed under a compound Poisson assumption, with truncated exponential claims. It is shown that the introduction of a high deductible would increase the variability of payments and the efficiency of the rating system for most policyholders 1 .
\end{abstract}

\section{KEYWORDS}

Motor insurance rating; bonus-malus systems; deductibles.

\section{INTRODUCTION}

Traditional merit-rating or bonus-malus systems (BMS) suffer from two major drawbacks.

(i) The severe penalties needed to compensate no-claim discounts cannot be enforced, for commercial reasons. A continuous increase of the average discount follows, until the system reaches stationarity. This forces insurers to raise premiums annually. After a few years, most policies cluster in the high-discount classes, and there is no significant premium differentiation between good and bad drivers.

(ii) Penalties after an accident at fault are independent of damages. This creates a bonus-hunger phenomenon, that induces policyholders to bear small claims themselves, in order to avoid future premium increases. In some cases, it is of the policyholder's interest to pay substantial amounts to their victims. This creates a feeling of unfairness, and encourages hit-and-run behaviour.

\footnotetext{
1 The authors would like to thank Messrs. Ted Chung and Chen-Yeh Lai, who kindly provided detailed information about the Taiwanese merit-rating system and loss distributions.
} 
Holtan (1994) suggests an ingenious alternative to BMS rating: a highdeductible system (HDS). In this system, the premium would only provide coverage for the part of the losses in excess of a high deductible $D$. Policyholders who cannot afford to pay this amount could borrow it from the company, and reimburse this loan over a small number of years.

The implementation of a HDS could eliminate the two main drawbacks of BMS: the premium income would not decrease over time, and, since the penalty after a claim never exceeds the claim amount (except for interest on the loan), the hunger for bonus effect would be eliminated.

In this paper, we use simulation and a simple compound Poisson model to compare Holtan's proposal to the BMS in force in Taiwan, a system which is rather "tough" to policyholders (see LemaIRE and $\mathrm{Z}_{\mathrm{l}}, 1994$ ). It is shown that high deductibles improve the efficiency of the rating system, but increase the variability of the payments, as measured by the coefficient of variation. The Taiwanese BMS is analysed in Section 2. The HDS is studied in Section 3. Practical considerations are to be found in Section 4. Section 5 summarizes findings and suggest further research.

\section{ANALYSiS OF THE TAIWANESE BMS}

Our benchmark policyholder is a Taiwanese driver, whose annual number of claims is Poisson distributed, with a parameter $\lambda=0.10$. At time 0 , he enters the BMS described in Table 1, in class 4.

TABLE 1

TAIWANESE BONUS-MALUS SYSTEM

\begin{tabular}{lccccccc}
\hline \hline Class & \multicolumn{7}{c}{ Class after } \\
\cline { 3 - 8 } & $\begin{array}{c}\text { Premium } \\
\text { Level }\end{array}$ & 0 & 1 & $\begin{array}{c}2 \\
\text { claims }\end{array}$ & 3 & 4 & $5+$ \\
\hline 9 & 150 & 3 & 5 & 6 & 7 & 8 & 9 \\
8 & 140 & 3 & 5 & 6 & 7 & 8 & 9 \\
7 & 130 & 3 & 5 & 6 & 7 & 8 & 9 \\
6 & 120 & 3 & 5 & 6 & 7 & 8 & 9 \\
5 & 110 & 3 & 5 & 6 & 7 & 8 & 9 \\
4 & 100 & 3 & 5 & 6 & 7 & 8 & 9 \\
3 & 80 & 2 & 5 & 6 & 7 & 8 & 9 \\
2 & 65 & 1 & 5 & 6 & 7 & 8 & 9 \\
1 & 50 & 1 & 5 & 6 & 7 & 8 & 9 \\
\hline
\end{tabular}

Effects of inflation are removed by assuming that premiums, losses, deductibles, ..., escalate according to the same index.

The evolution of the policyholder among the classes has been simulated for 30 years, the time it takes for system to reach a stationary state. Figure 1 shows that the expected premium level constantly decreases over time, reaching a level 


\section{PREMIUM MEAN AND STANDARD DEVIATION}

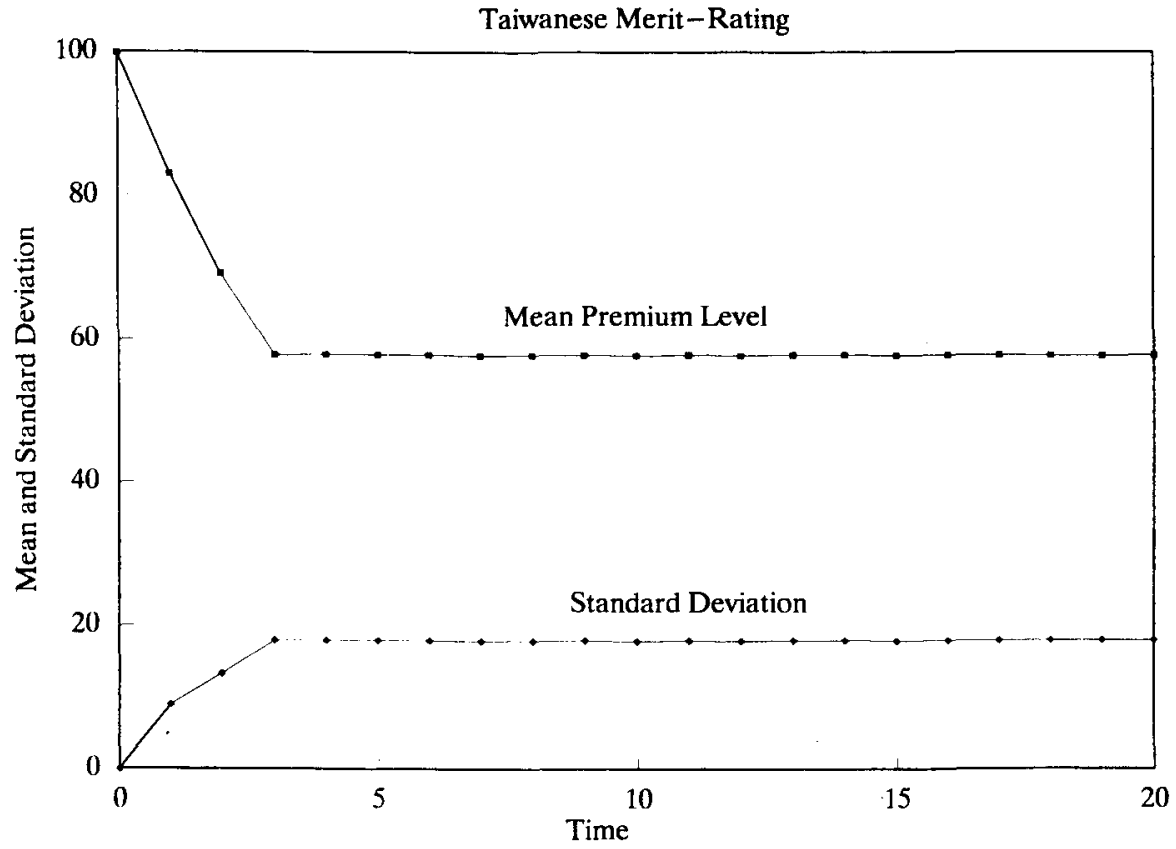

Figure 1.

of 57.75 at time $30^{2}$. The standard deviation of payments increases during the first 3 years, the time it takes for the best policyholders to reach class 1 . Then it stabilizes around 17.89. As figures are expressed in premium levels in this section, and in dollars in Section 3, a dimension-less parameter has to be used for comparison purposes: the coefficient of variation (standard deviation divided by mean). For the benchmark Taiwanese driver, the coefficient of variation increases for 3 years, then stabilizes around 0.31 (see Fig. 2). Figure 3 shows the coefficient of variation as a function of $\lambda$, when the system is stationary.

Simulation was also used to compute the efficiency, the elasticity of the stationary premium with respect to the claim frequency. If $P(\lambda)$ denotes the stationary premium for a policyholder with a claim frequency $\lambda$, the efficiency curve $\varphi(\lambda)$ is defined as the relative increase of the premium, divided by the relative increase of the claim frequency (see LOIMARANTA, 1972, and LEMAIRE, 1985).

$$
\varphi(\lambda)=\frac{\frac{d P(\lambda)}{P(\lambda)}}{\frac{d \lambda}{\lambda}}
$$

\footnotetext{
2 The observed average premium level in Taiwan is higher than that, due to the constant flow of new policyholders entering the system in a high class. However, since this note analyses two rating systems from a policyholder's point of view, new entries in the BMS are not considered.
} 


\section{PREMIUM COEFFICIENT OF VARIATION}



Figure 2.

\section{COEFFICIENTS OF VARIATION}

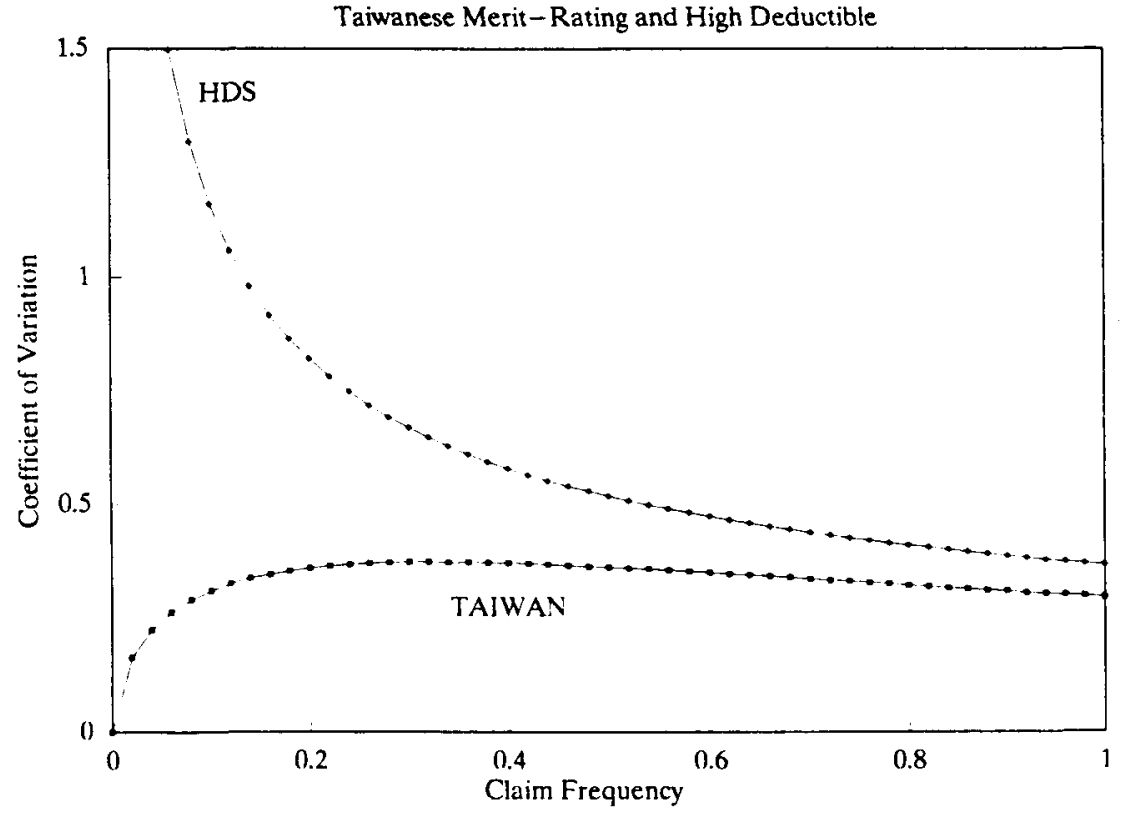

FIGURE 3. 
Ideally, the efficiency should be close to 1 . In practice, the efficiency of most BMS in force around the world is much lower (LEMAIRE, 1988). For the Taiwanese BMS, the efficiency is very low for the most common values of $\lambda$ $(\lambda \leq 0.10)$; it peaks at 0.3 for claim frequencies in the $[0.65-0.80]$ range (see Fig. 4). For $\lambda=0.10, \varphi(0.10)=0.1155$.

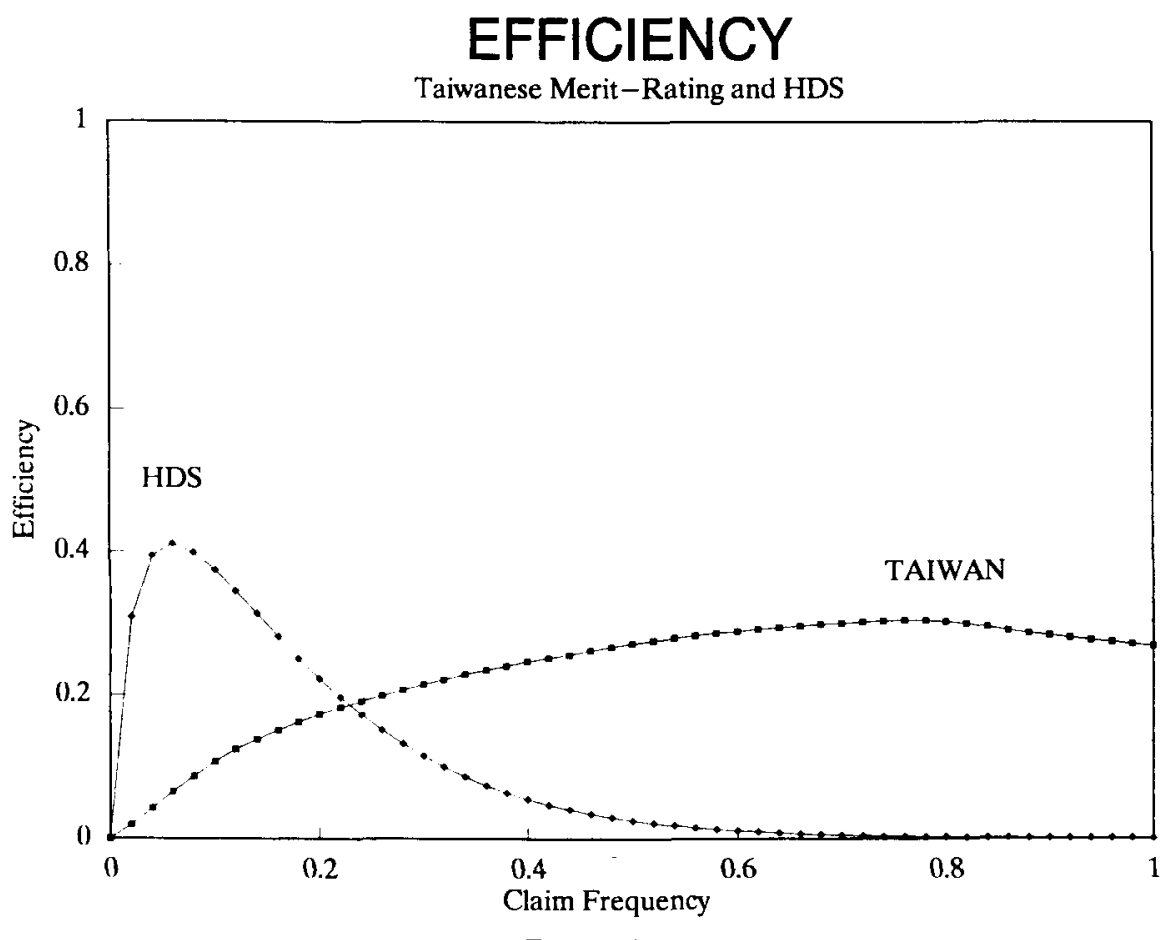

Figure 4.

\section{3. analysis of the High-Deductible System}

Major assumptions for the HDS analysis are:

* Deductible: $D=\$ 3,000$

* Policyholders always borrow the entire loss amount $L$ (up to $\$ 3,000$ ) from their insurer. Loans are reimbursed over a 5-year period, with decreasing amortization. A sum-of-the-digits principal repayment schedule is adopted: after a claim, $5 / 15$ of the principal is repaid with the next annual premium, $4 / 15$ the year after, ... All accidents occur in the middle of the year. The loan's interest rate is $3 \%$, a low value since we assumed an inflation-free environment. This leads to the following payment schedule, for an accident that occurred at time $t-1 / 2$ and a loan $L=\min (D$, claim cost). 


\begin{tabular}{lc} 
Time & Payment \\
$t$ & $.3483 \mathrm{~L}$ \\
$t+1$ & $.2867 \mathrm{~L}$ \\
$t+2$ & $.2120 \mathrm{~L}$ \\
$t+3$ & $.1393 \mathrm{~L}$ \\
$t+4$ & $.0687 \mathrm{~L}$ \\
\hline Total & $1.0550 \mathrm{~L}$
\end{tabular}

* The annual gross premium, without a deductible, is $\$ 500$. With $15 \%$ taxes, a $15 \%$ commission, and $10 \%$ operating expenses, the net premium is $\$ 300$.

* Claim amounts are exponentially distributed, with parameter $\mu=1 / 3$ (using a $\$ 1,000$ currency unit).

As a consequence of these assumptions, the introduction of a $\$ 3,000$ deductible reduces the net premium to a basic premium

$$
\lambda \int_{D}^{\infty}(x-D) \mu e^{-\mu x} d x=\frac{\lambda}{\mu} e^{-\mu D}
$$

For the benchmark policyholder, the net premium is reduced from $\$ 300$ to $\$ 110.36=0.1104$.

Aggregate claims up to $D$ form a compound Poisson process $S$, with a truncated exponential claim amount $X$. The first two moments of $X$ are

$$
\begin{aligned}
E(X) & =\int_{0}^{D} x \mu e^{-\mu x} d x+D \int_{D}^{\infty} \mu e^{-\mu x} d x \\
& =\frac{1-\mu e^{-\mu x}}{\mu}=1.8964 \\
E\left(X^{2}\right) & =\int_{0}^{D} x^{2} \mu e^{-\mu x} d x+D^{2} \int_{D}^{\infty} \mu e^{-\mu x} d x \\
& =\frac{2}{\mu^{2}}\left(1-e^{-\mu D}\right)-\frac{2 D}{\mu} e^{-\mu D}=4.7563
\end{aligned}
$$

For a compound Poisson process (see for example BowErs et al., 1986, chapter 11),

$$
\begin{aligned}
E(S) & =\lambda E(X)=(0.10)(1.8964)=0.1896 \\
\operatorname{Var}(S) & =\lambda E\left(X^{2}\right)=(0.10)(4.7563)=0.4756
\end{aligned}
$$

Disregarding all expenses, the expected payment for the first policy year consists only of the basic premium 0.1104. Expected payments (premium + 
loan repayments) for the second year amount to

Basic premium $+[($ expected claim number $) \cdot($ expected claim cost $) \cdot$ (0.3483 loan payment)]

$$
=\frac{\lambda}{\mu} e^{-\mu D}+\lambda \frac{1-e^{-\mu D}}{\mu}(0.3483)=0.1764
$$

The variance of payments for the second year is

$$
\operatorname{Var}(S) \cdot(0.3483)^{2}=0.0577
$$

Expected payments for the third year are

Basic premium $+[($ expected claim number $) \cdot($ expected claim cost $) \cdot$ $(0.3483$ of second-year loan +0.2867 of first-year loan $)]=0.2308$.

The variance is $\operatorname{Var}(S) \cdot\left(0.3483^{2}+0.2867^{2}\right)=0.0988$.

The system reaches stationarity after five years. Expected payments for the sixth year are

Basic premium $+[($ expected claim number $) \cdot($ expected claim cost $) \cdot$ $(0.3483$ of 5 th-year loan +0.2867 of 4 th-year loan +0.2120 of 3 rd-year loan +0.1393 of 2 nd-year loan +0.0687 of 1 st-year loan) $]=0.31043$.

Average stationary payments exceed the net premium of 0.3 , since policyholders are constantly paying back loans. Expected payments, variances, and coefficients of variation are presented in Table 2. Figure 2 shows that, for a policyholder with $\lambda=0.10$, the variability of payments is at all times much higher under the HDS than under the Taiwanese BMS. Figure 3 shows that, for all usual values of $\lambda$, the coefficient of variation is higher under the HDS.

TABLE 2

HDS EXPECTED PAYMENTS, VARIANCE, AND COEFFICIENT OF VARIATION

\begin{tabular}{lcccc}
\hline Time & Year & $\begin{array}{c}\text { Expected } \\
\text { Payments }\end{array}$ & Variance & Coef. of variation \\
\hline 0 & 1 & 0.1104 & 0 & 0 \\
1 & 2 & 0.1764 & 0.0577 & 1.3616 \\
2 & 3 & 0.2308 & 0.0968 & 1.3481 \\
3 & 5 & 0.2710 & 0.1182 & 1.2686 \\
4 & 5 & 0.2974 & 0.1274 & 1.2002 \\
$5,6,7, \ldots$ & 6 and after & 0.3104 & 0.1296 & 1.1599 \\
\hline
\end{tabular}

For the basic Compound Poisson process with exponential claims the coefficient of variation of losses is $\sqrt{2} / \lambda=4.4721$, for $\lambda=0.1$. The highdeductible system would reduce the coefficient of variation of policyholders' 
payments to 1.1599. Coefficients of variation in excess of 1 would probably be considered as too high by regulators and consumers. A reduction of payments variability can be achieved by

(i) spreading the loan reimbursements over more than five years, and/or

(ii) adopting a loan reimbursement schedule with level payments.

For instance, a five-year loan with equal payments of $.2152 \mathrm{~L}$ would increase stationary expected payments to .3144 , but reduce their variance to .1101 . The coefficient of variation decreases to 1.0552 , a $9.02 \%$ reduction. If the loan is spread out to 10 years, with equal payments of $.1155 \mathrm{~L}$, expected payments increase to .3331 , their variance decreases to .0635 , and the coefficient of variation drops to a more acceptable .7564 .

Stationary payments for a policyholder with claim frequency $\lambda$ amount to

$$
\begin{aligned}
P(\lambda) & =0.1104+\frac{\lambda}{\mu}\left(1-e^{-\mu D}\right) \cdot(1.055) \\
& =0.1104+0.3165\left(1-e^{-10 \lambda}\right)
\end{aligned}
$$

if the basic premium ${ }^{3}$ is set by the company at 0.1104 . Consequently the efficiency is

$$
\varphi(\lambda)=\frac{3.165 \lambda e^{-10 \lambda}}{0.1104+0.3165\left(1-e^{-10 \lambda}\right)}
$$

Figure 4 shows that the efficiency of the HDS is higher than the efficiency of the Taiwanese BMS for the most common values of $\lambda$ (under 0.22 ). For $\lambda=0.10, \varphi(0.10)=0.3751$. For the larger $\lambda$, the BMS is more efficient. Since most policyholders have a low $\lambda$, the computation of an average efficiency $\varphi$ using any realistic structure function $u(\lambda)$

$$
\varphi=\int_{A} \varphi(\lambda) u(\lambda) d \lambda
$$

would provide a better efficiency for the HDS. $u(\lambda)$ is the density function of $\lambda$ in the insurer's portfolio.

\section{PRACTICAL CONSIDERATIONS}

The implementation of a HDS instead of a BMS would lead to several practical problems:

1. Surcharges and discounts for other classification variables would need to be revised. For instance, in many countries, inexperienced drivers have to pay

\footnotetext{
${ }^{3}$ In a definition of the efficiency from an insurer's point of view, the basic premium of 0.1104 would be replaced by $(\lambda / \mu) e^{-\mu D}$. From a policyholder's point of view, however, the basic premium is exogeneous, and not a function of his own $\lambda$.
} 
a hefty surcharge. In addition, they also pay an implicit penalty, as they have to access the BMS at a level which is higher than the average stationary level. As this surcharge would disappear, explicit penalties for inexperience need to be reinforced.

2. The administration of a BMS is extremely inexpensive, and routinely handled by company computers. A HDS would lead to much higher expenses, since the insurer has to examine the credit worthiness of the policyholder before each annual period.

3. A bad (or unlucky) policyholder could face considerable debt and possibly personal bankruptcy. This is the kind of situation insurance is meant to avoid.

4. As a partial remedy for possible insolvencies, Holtan suggests to open an account for each policyholder. Each year, a specified amount would be set aside, to build up an individual risk reserve to cover future deductibles. Creating such accounts would eliminate the solvency problem for most experienced policyholders. However, it would do little to help young drivers, who not only form the group with the highest accident rate, but also the group with the worse credit rating. At most, policyholders could be induced to save the gross premium reduction created by the introduction of the deductible. In our benchmark situation, a $\$ 3,000$ deductible reduces the gross premium by $\$ 190$. So $\$ 190$ could be saved annually in the account. If the savings account accrue $3 \%$ (real) interest, it will take 13 years to save the amount of just one deductible.

5. With a HDS, many policyholders would in practice be prevented from switching to a new company after a claim, since the former insurer would demand a full reimbursement of the loan. This goes against current regulatory trends and creates an adverse selection process: claim-free policyholders would be free to leave a company, while policies with claims could not be eliminated from the portfolio and sent to the residual market.

6. Taxes, commissions, and operating expenses have been disregarded in the preceding analysis. For simplicity, assume the operating expenses of the HDS are $\$ 50$, like in a BMS. It seems impossible to include these expenses in the loan reimbursement schedule. Commissions and taxes are not paid on deductibles. A policyholder, who has incurred a $\$ 3,000$ loss, will never accept to repay $\$ 5,000$, in order to provide $\$ 750$ to his broker, $\$ 750$ to his government, and $\$ 500$ to compensate the company for operating expenses. Since the broker, the government, and the insurer will not accept a decrease of their revenue, all of these expenses will need to be included in the basic premium, that covers losses above $\$ 3,000$. So the gross premium of a benchmark policyholder would be $\$ 310(\$ 110$ net premium $+\$ 200$ expenses, tax and commission). $64.5 \%$ of the gross premium would be needed to cover expenses. While in practice such a high figure may be reached for some low-premium or high-deductible policies, it is certainly excessive for compulsory auto third party coverage. 


\section{EFFECT OF EXPENSES ON HDS}

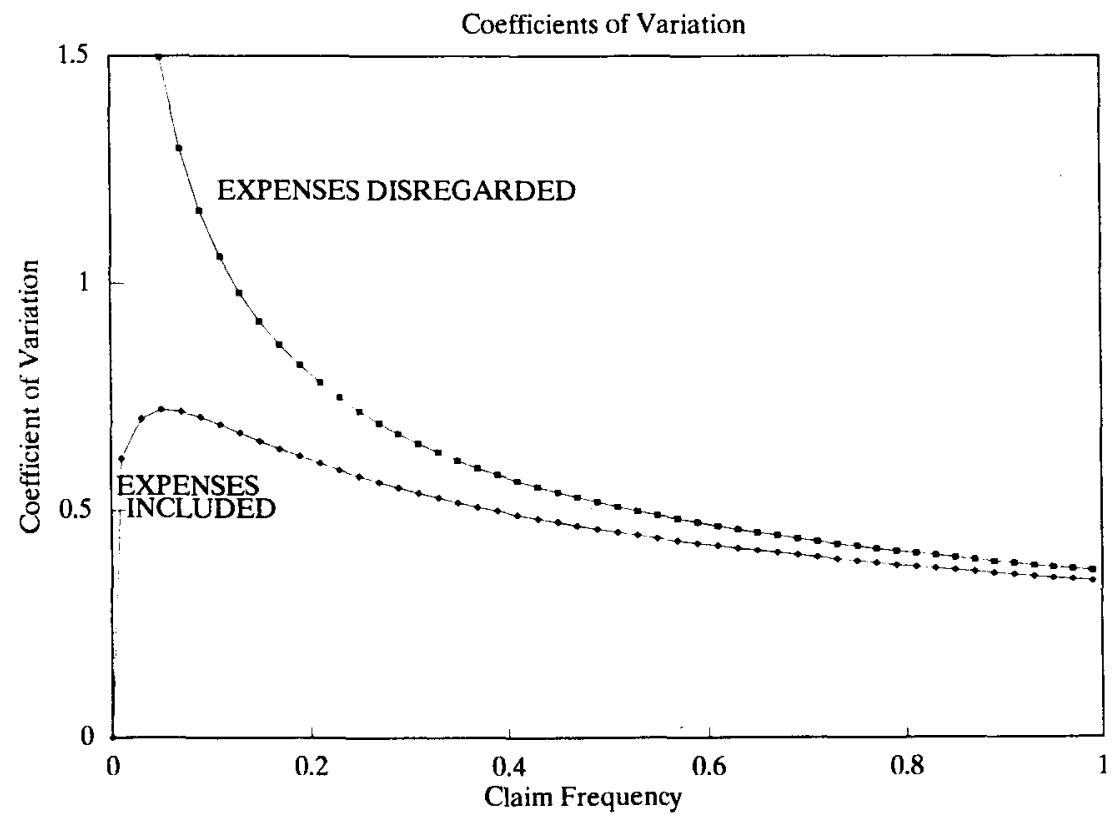

FIGURE 5 .

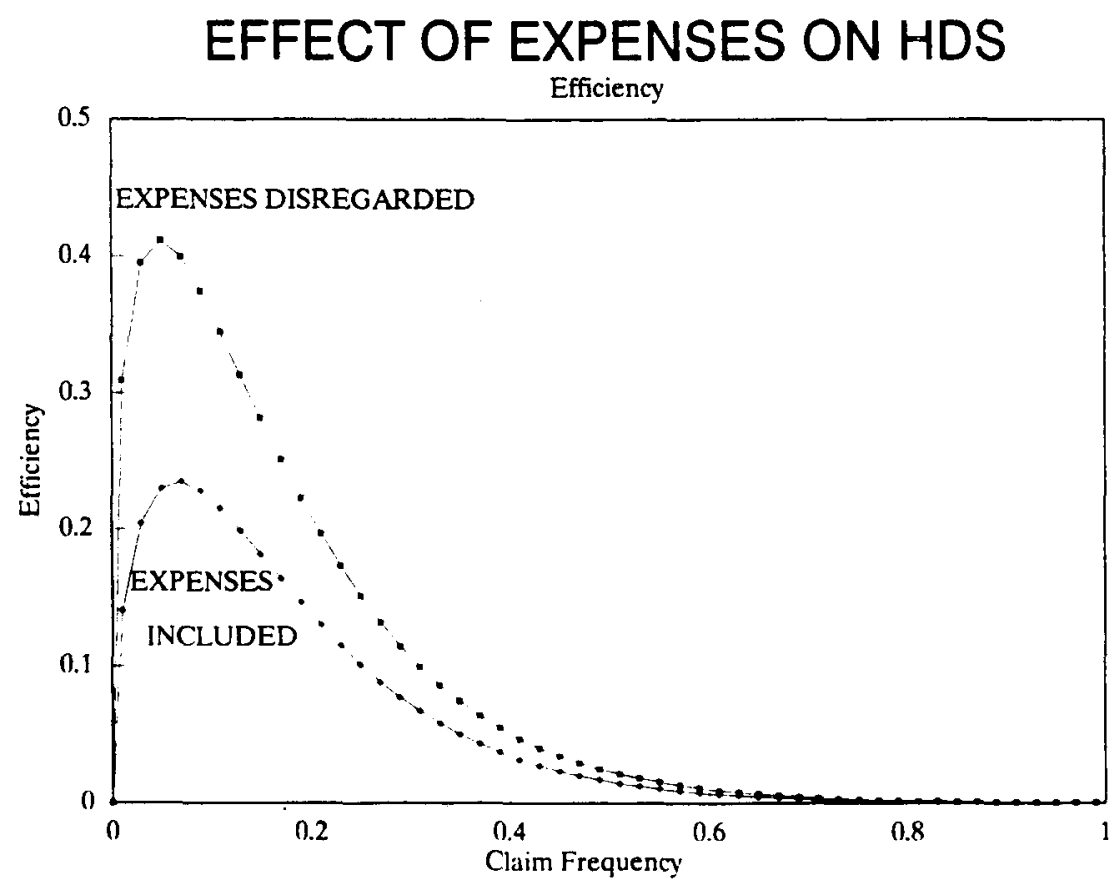

FIGURE 6. 
The inclusion of all expenses into the basic premium has another important consequence: a decrease of the efficiency and the payments coefficient of variation of the HDS. In a traditional BMS, expenses are proportional to the premium level, and bad drivers pay more commission, tax, and operating expenses. In a HDS, all policyholders contribute equally towards expenses. This reduces relative premium differentiation, and has a depressing effect on the efficiency curve and on the coefficient of variation of payments (see Fig. 5 and 6).

7. In the preceding analysis, the deductible has been set rather arbitrarily at $\$ 3,000$, following a suggestion by Holtan to set the deductible around the mean claim cost. If the HDS is ever implemented, the value of the deductible will probably be decided by practical considerations, and not as the result of sophisticated modelling. Holtan has presented a model, based on the minimisation of a quadratic expected utility function, that would provide an "optimal" deductible, after lengthy calculations. A simpler optimisation criterion coud be based on the efficiency. For instance, one could select the deductible in such a way as to maximise $\varphi(0.10)$. The first derivative (with respect to $D$ ) of $\varphi(0.10)$ is easily calculated, and a numerical procedure leads to an optimal deductible of $\$ 2,941$, very close to the value arbitrarily selected. Figure 7 compares the efficiency curve for various deductibles. It shows that $\varphi(0.10)$ is not an increasing function of $D$. A very large $D$ improves the efficiency for small $\lambda$ 's, but reduces $\varphi(0.10)$.

\section{Efficiency with Varying Deductibles}

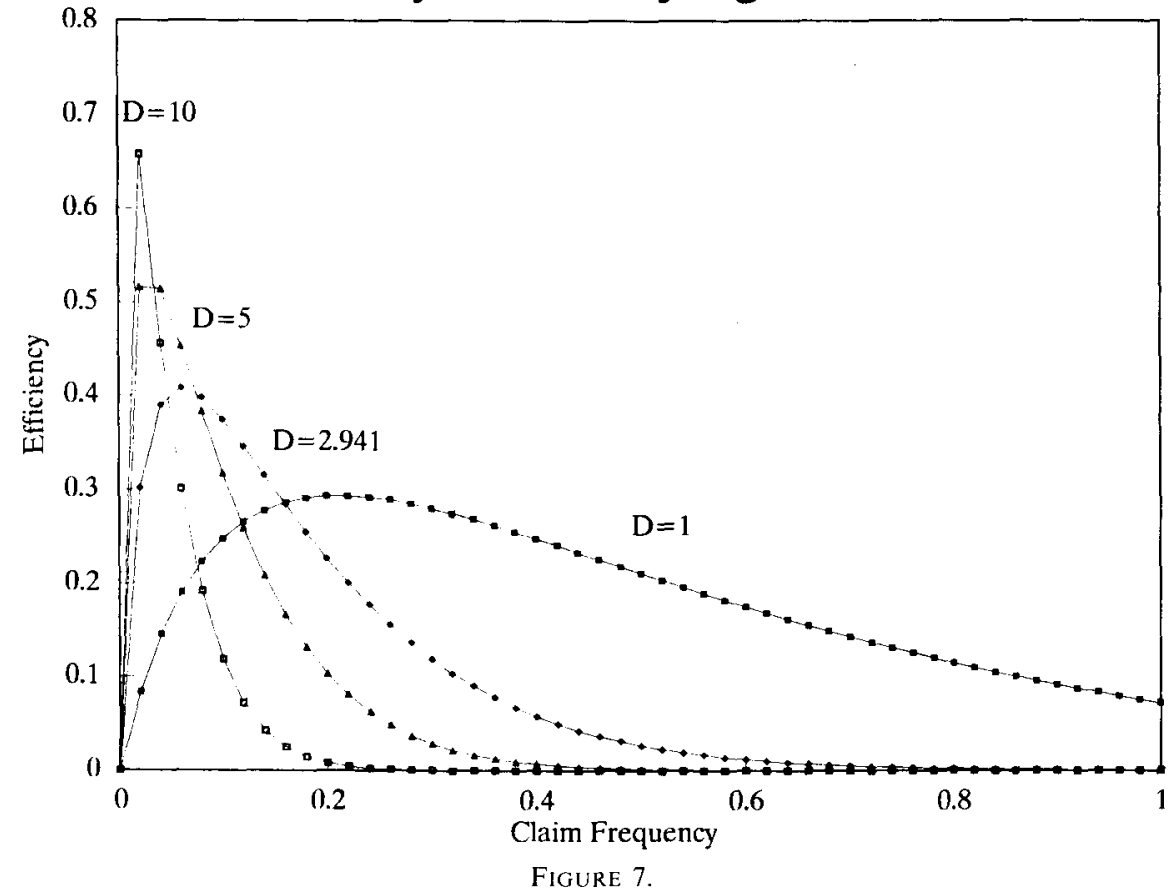




\section{Conclusions}

Compared to a traditional bonus-malus system, a high deductible system

1. reaches a steady state much faster;

2. increases premium income during early years;

3. has a higher efficiency for the most common values of the claim frequency; and

4. has a higher variability of payments for all policyholders.

Of course the first three points are in favour of the HDS, while point 4 is a very important drawback, that will probably prevent the application of a HDS in practice. Further research might be needed to improve Holtan's proposal. For instance, one should investigate the impact of less severe forms of claim sharing than a straight deductible, such as proportional co-payments under $D$, or annual vs. per claim deductibles.

Finally, it should be pointed that a HDS would be a good application of the "bancassurance" concept, since both insurance (above the deductible) and banking (the loan under the deductible) expertise would be needed to manage the system. The banking segment of the industry would be induced to develop savings vehicles that would guarantee the repayment of the loans.

\section{REFERENCES}

Bowers, N., Gerber, H., Hickman, J., Jones, D. and Nesbitt, C. (1986) "Actuarial Mathematics." Society of Actuaries, Schaumburg, Illinois.

Holtan, J. (1994) "Bonus Made Easy." ASTIN Bulletin 24.

Lemaire, J. (1985) “Automobile Insurance: Actuarial Models." Kluwer Nyhoff Publishing Co, Boston, Massachussetts.

LemaIRe, J. (1988) “A Comparative Analysis of Most European and Japanese Bonus-malus Systems." Journal of Risk and Insurance LV, $660 \% 681$.

Lemaire, J. and ZI, H. (1994) "A Comparative Analysis of 29 Merit-Rating Systems." Submitted.

Lomaranta, K. (1972) "Some Asymptotic Properties of Bonus Systems." ASTIN Bulletin 6, $233-245$.

JEAN Lemaire AND Hongmin ZI

Department of Insurance, and Risk Management,

Wharton School, 3641 Locust Walk,

University of Pennsylvania Philadelphia, PA 19104-6218, U.S.A. 